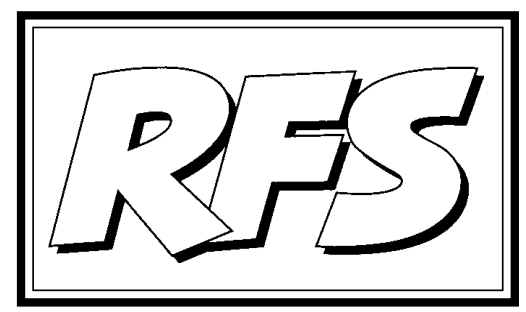

Revista de Fomento Social, 56 (2001), 399-432

\title{
Los mercados monetarios españoles. Evolución y perspectivas $^{1}$
}

Ma del Carmen LÓPEZ MARTíN ${ }^{2}$

\section{Introducción. Concepto, funciones y clasificación}

Uno de los aspectos que más atención suscita en cualquier economía es el funcionamiento de sus mercados financieros. Ello es así porque éstos constituyen los lugares (o procedimientos, ya que no es necesaria la existencia de un lugar físico) en los que se intercambian los instrumentos financieros (la

1 Este artículo es un resumen de algunos de los aspectos más significativos analizados en la tesis doctoral de la autora, titulada La creación de los mercados monetarios españoles. Formación y futuro.

2 Profesora de Mercados e instrumentos financieros, del departamento de Economía General, Ciencias jurídicas y Sociología de la Facultad de CC. EE. y Empresariales-ETEA, adscrita a la Universidad de Córdoba

La autora agradece las sugerencias y comentarios realizados por Adolfo Rodero Franganillo. 
contraprestación es, en la mayor parte de las ocasiones, dinero ${ }^{3}$ ) y se fijan sus precios. Como es sabido, los instrumentos financieros no son sino un reconocimiento de deuda a favor de su poseedor y en contra de su emisor, por tanto, son valores ${ }^{4}$ que constituyen una forma de mantener la riqueza para quienes los poseen y un pasivo para el agente que los generó.

Dentro de los mercados financieros, existen múltiples clasificaciones y, dado su carácter (no son incompatibles entre sí), un mismo mercado puede encuadrarse en más de un tipo diferente, en función del criterio que se adopte. Así, un primer grupo de clasificaciones atiende al instrumento financiero intercambiado; en función de ésta, cada instrumento concreto da lugar a un mercado diferente. Ello, sin embargo, no supone una ayuda especialmente valiosa, dada la gran variedad de instrumentos existentes, por eso, dentro de ella, se establecen distintos grupos en función de la característica de los instrumentos que se considera más representativa para su estudio ${ }^{5}$.

Precisamente si se utiliza como criterio de clasificación de los mercados financier os la liquidez o el plazo de amortización de los instrumentos negociados, se distingue entre mercados monetarios y mercados de capitales ${ }^{6}$, correspondiendo los primeros, en general, a aquéllos en los que se emiten y negocian instrumentos con corto plazo de amortización y elevada liquidez, mientras que en los segundos se intercambian valores con vencimiento a medio y largo plazo ${ }^{7}$. En concreto, el Banco Central Europeo (BCE) (1998) define los instrumentos del mercado monetario como instrumentos representativos de deuda transferibles, negociados normalmente en el mercado

3 Que también es un instrumento financiero.

4 No empleamos esta denominación en el sentido de soporte material de un instrumento financiero, ya que actualmente, no todos los instrumentos financieros están materializados en títulos valores, sino que se emplean técnicas de emisión (como las anotaciones en cuenta) que suponen una desmaterialización de los instrumentos.

5 Se puede optar por diferentes aspectos: naturaleza jurídica, liquidez, forma de rentabilidad, negociabilidad, etc.

6 Tanto en un caso como en otro, se emplea la expresión en plural por tratarse de un conjunto de mercados, y no un único mercado en el que se negocie un instrumento específico.

7 Por acuerdo se considera que el corto plazo abarca el año, aunque a veces se amplía hasta los 18 meses (criterio que usa, por ejemplo, el Banco de España). Por el contrario, el medio y largo plazo se aplica a vencimientos superiores al año (o los 18 meses, según el criterio adoptado para los mercados monetarios). 
monetario (por ejemplo, certificados de depósito, pagarés de empresa, aceptaciones bancarias, pagarés del Tesoro y de autoridades locales, etc.), que tienen las siguientes características: liquidez, profundidad del mercado, certidumbre en su valor, bajo riesgo detipo de interés y bajo riesgo de crédito.

En numerosas ocasiones se indica que la existencia y el desarrollo de los mercados monetarios tiene efectos beneficiosos para el funcionamiento de la economía en general y del sistema financiero, en particular. Ello se justifica, normalmente, por las funciones que se les asignan. Lógicamente, estas funciones son, en parte, comunes a las que realizan genéricamente todos los mercados financieros; otras, sin embargo, se les suelen atribuir con carácter más específico. De forma resumida, las que habitualmente se les asignan se pueden concretar como sigue ${ }^{8}$ :

- La política monetaria se ejecuta en los mercados monetarios y su existencia contribuye al logro de los objetivos de la misma. En general, (aunque existen matices importantes), en los países desarrollados se sigue una política monetaria de control de la liquidez como medio de contener la inflación ${ }^{9}$. Para que pueda ejecutarse dicha política, es necesaria la existencia de un mercado en el que la autoridad monetaria pueda fijar el volumen de liquidez bancaria, distribuirlo entre las distintas instituciones y fijar su precio. Por otra parte, este mercado habrá de estar suficientemente desarrollado para que así la intervención de la autoridad pueda realizarse con los instrumentos suficientes y adecuados, de forma que las variables se ajusten con eficiencia y suavidad. En cualquier caso, la relación entre la política monetaria y estos mercados es biunívoca: por un lado, esta política necesita la existencia de los mercados monetarios; por otra parte, éstos ejercen una influencia importante en el diseño e instrumentación de la misma.

Los mercados monetarios contribuyen a que se forme una estructura adecuada de los tipos de interés. Ello es posible porque en estos

8 En la exposición que aparece a continuación hay que tener en cuenta que la mayoría de estas funciones se han utilizado como justificación de la conveniencia de que estos mercados se desarrollen en España, por lo que son específicas del caso español. A pesar de ello, se tratan, en la medida de lo posible, de forma general.

9 Normalmente, se suelen establecer los objetivos de política monetaria en términos de crecimiento de una magnitud representativa de la cantidad de dinero, o bien de unos niveles para los tipos de interés o el mantenimiento de un determinado valor del tipo de cambio o de la tasa de inflación. 
mercados se van a establecer unos tipos a corto plazo que pueden servir de base para la fijación de la estructura de tipos de interés en el resto de los mercados financieros. Lógicamente, para que puedan jugar este papel, los tipos de interés que se formen en los mercados monetarios han de ser suficientemente significativos por el volumen de las operaciones a que corresponden; asimismo deben evolucionar de forma continua y sin movimientos erráticos en función de la mayor 0 menor restricción de la política monetaria. Por otra parte, es preciso recordar que el resto de los tipos de interés se formarán teniendo en cuenta los diferentes plazos, seguridad y liquidez de las operaciones financieras, así como las expectativas de los agentes económicos.

- La eficiencia de las decisiones financieras de los agentes económicos puede aumentar con la información que proporcionan los mercados monetarios. Si los mercados monetarios funcionan eficientemente, facilitan una información que permite conocer a los diferentes agentes la situación en los mismos, por lo que pueden establecer sus decisiones de ahorro, inversión o política económica de la forma más adecuada. Como consecuencia, aumenta la preocupación por la gestión de la tesorería de las entidades (sean o no financieras), ya que existe un mecanismo por el que se pueden invertir los excedentes de liquidez y obtenerla a corto plazo a precios fijados por el mercado; en definitiva, la existencia de mercados monetarios supone un coste de oportunidad elevado para los saldos de tesorería ociosos. Por otra parte, se piensa que el aumento de la eficiencia en la gestión de los recursos a corto plazo puede contribuir a aumentar la del resto de los recursos financieros.

Los mercados monetarios permiten asignar los recursos financieros y obtener financiación. Esta última función es algo obvia para cualquier mercado financiero, pero en ocasiones no se asocia expresamente a los monetarios, ya que se les suele relacionar con mercados en los que los intermediarios hacen negocio con otros intermediarios o con particulares. Sin embargo no se puede perder de vista que en ellos intervienen entidades que pueden obtener recursos en condiciones adecuadas de plazo y tipo de interés; a la vez, a través de los mismos se podrán llevar los recursos a quienes puedan pagar más por ellos y, por lo tanto, los destinarán a actividades más rentables, lo que redundará positivamente en el resto del sistema económico. Un aspecto particular de este hecho es su contribución a la financiación ortodoxa del déficit público, 
ya que la existencia de unos mercados monetarios suficientemente desarrollados permite al Tesoro público emitir títulos a corto plazo que puedan ser adquiridos por el público en general. Si se hace así, se puede evitar el recurso al banco emisor ${ }^{10}$ que, como ya es sabido, provoca un aumento de la liquidez. Este incremento del dinero en circulación tiene efectos inflacionistas y dificulta el control monetario ${ }^{11}$.

De la definición que se indicó para los mercados monetarios, se deduce que su contenido viene expresado por los instrumentos que se negocian en ellos. Puesto que en este artículo el objeto de estudio es el caso español, nos centramos en este país concreto; no obstante, es preciso aclarar que, para la generalidad de los países, los instrumentos negociados son los que reúnen las características mencionadas anteriormente (corto plazo, liquidez y riesgo reducido), con independencia de la denominación que reciban y de los aspectos específicos que afecten a cada país. Centrándonos, pues, en España, los mercados quese incluyen dentro de los monetarios y los instrumentos negociados en ellos son los expuestos en el cuadro 1. En los párrafos siguientes se describen de forma breve.

\section{a) Mercados de activos de caja}

Se trata de los mercados en los que únicamente intervienen las instituciones financieras autorizadas, que realizan operaciones entre sí, o bien entre ellas y el Banco de España ${ }^{12}$. Esta duplicidad de operaciones, hace que se

10 Que puede ser o no posible en función de la legislación vigente en cada momento (en el caso de España, la financiación del Banco de España al Tesoro está prohibida desde la entrada en vigor de la ley de autonomía del Banco de España en 1994).

11 Este aspecto no es totalmente positivo, pues encierra peligros que, en cierta medida, se han puesto de manifiesto en España. Aunque estos efectos se comentan posteriormente, se pueden adelantar aquí algunos a título de ejemplo, tales como el excesivo protagonismo de los valores públicos en los mercados monetarios y el aumento de la carga financiera del déficit debido al volumen colocado a los tipos de interés existentes en estos mercados.

12 Hasta enero de 1999, el Banco de España era el responsable del diseño y ejecución de la política monetaria en España, mientras que, desde dicha fecha esta tarea es responsabilidad del BCE y del Sistema Europeo de Bancos Centrales (SEBC). No obstante, los acuerdos a los que se ha llegado sobre la descentralización de las operaciones del SEBC implican que las operaciones relacionadas con la ejecución de la política monetaria única en cada país se realizan por el banco central correspondiente (siguiendo los acuerdos y directrices establecidos por el BCE), de ahí que, en definitiva, en España el Banco de España sigue interviniendo en los mercados de activos de caja. 
suela diferenciar entre el mercado interbancario privado y las operaciones realizadas con la intervención del Banco de España (o también denominadas de regulación monetaria). En su origen, se trataba sólo de un mercado de depósitos entre instituciones financieras, aunque con posterioridad se comenzaron a realizar también en él operaciones dobles (repos y simultáneas) $^{13}$. Los mercados que se incluyen (o se han incluido en el pasado ${ }^{14}$ ) en este grupo son los siguientes:

a.1) Mercados interbancarios de depósitos no transferibles y transferibles.

a.2) Mercado de certificados del Banco de España ${ }^{15}$.

a.3) Operaciones con valores públicos entre intermediarios financieros. ${ }^{16}$

a.4) Mercado derivado del coeficiente de inversión.

13 Las operaciones dobles son, en general, operaciones de compra (venta) de determinados títulos con pacto de retrocesión (es decir, de reventa o recompra, según los casos), transcurrido el plazo de la operación. Dentro de ellas, se puede distinguir entre repos y simultáneas, en función de la disponibilidad de los valores que son objeto de cesión durante el período que dura la misma (la disponibilidad es plena en las simultáneas y limitada en los repos).

A finales de 1998 en la ley 37/1998 de reforma de la ley 24/1988 del mercado de valores se eliminó la clasificación de las operaciones dobles entre repos y simultáneas, quedando únicamente éstas últimas con este carácter de operaciones dobles. No obstante, creemos que es más claro mantener esta clasificación en términos generales, al menos conceptualmente, aunque en la regulación esta distinción no se haya mantenido.

14 El mercado de certificados del Banco de España (CBE) y el derivado del coeficiente de inversión ya han desaparecido, al haber sido amortizados los CBE y desaparecer el mencionado coeficiente.

15 Los certificados del Banco de España se crearon en mayo de 1990, como consecuencia de la reducción del coeficiente de caja del $17 \%$ al $5 \%$ de los pasivos computables; ello forzó a impedir un incremento de liquidez que hubiera producido un fuerte aumento de las magnitudes monetarias. La forma de evitar esta situación fue obligar a suscribir estos certificados a las entidades sometidas al coeficiente.

16 Estas operaciones corresponden a uno de los segmentos del mercado de deuda pública anotada, si bien, al realizarse únicamente entre las entidades o entre éstas y el Banco de España, se separan de las restantes y se incluyen dentro de los mercados de activos de caja. 
CUADRO 1

Principales mercados monetarios españoles

\begin{tabular}{|l|l|}
\hline Mercados & Instrumentos \\
\hline Activos de caja & $\begin{array}{l}\text { Depósitos } \\
\text { Operaciones dobles } \\
\text { Activos computables en el coeficiente de inversión }\end{array}$ \\
\hline $\begin{array}{l}\text { Otros mercados } \\
\text { monetarios }\end{array}$ & $\begin{array}{l}\text { Deuda pública a corto plazo } \\
\text { Pagarés de empresa } \\
\text { Letras de cambio } \\
\text { Instrumentos a corto plazo emitidos por entidades } \\
\text { financieras }\end{array}$ \\
\hline
\end{tabular}

Fuente: Elaboración propia.

b) Otros mercados monetarios

Se incluyen en este grupo el resto de los mercados monetarios en los que se negocian instrumentos públicos y privados, materializados o no en títulos físicos, representativos de una deuda y caracterizados, como ya se ha indicado antes, por su corto plazo de amortización, alta liquidez y bajo riesgo. En concreto, en España existen los que indicados a continuación.

b.1) Mercado de deuda pública estatal a corto plazo.

b.2) Mercado de deuda pública no estatal a corto plazo.

b.3) Mercados de instrumentos emitidos por las empresas no financieras.

b.4) Mercados de instrumentos emitidos por los intermediarios financieros.

\section{La evolución de los mercados monetarios. Aspectos generales}

La idoneidad de los mercados monetarios para la consecución de las funciones a las que antes nos referíamos, ha llevado a que las autoridades económicas y otros agentes económicos y sociales hayan tratado de apoyar su desarrollo en España sobre todo desde los primeros años de la década de los 80. Pero además de ello, debe mencionarse que otros fenómenos de carácter fundamentalmente económico, institucional y financiero, han colaborado a su crecimiento y desenvolvimiento.

Nos referimos, por citar los que afectaron en mayor medida durante los 
primeros años en los que estos mercados comenzaron a desarrollarse, a las altas tasas de inflación, el bajo crecimiento del producto nacional, el elevado crecimiento del gasto y déficit públicos, la revolución tecnológica y un marco de mayor competencia dentro de los sistemas financieros junto con un creciente grado de innovación financiera. Por último, también es necesario indicar que determinadas situaciones legales propiciaron el auge, en unos casos, o bien el decaimiento y la práctica desaparición, en otros, de algunos de estos mercados o de los instrumentos negociados en ellos.

En cualquier caso, refiriéndonos a la evolución global de estos mercados, como característica más destacable puede señalarse que se ha producido un gran desarrollo de los mismos en poco tiempo, así como un crecimiento de su importancia y extensión desde mediados de la década de los setenta (punto en el que puede fecharse la aparición de estos mercados) hasta el momento actual. Este proceso ha ido acompañado no sólo de un aumento de las cantidades en ellos negociadas, sino que también resulta destacable la aparición de nuevos instrumentos (no sólo emitidos por las instituciones financieras, sino también por las administraciones públicas y empresas no financieras); así como la participación de un mayor número de agentes.

Todo el proceso de desarrollo de estos mercados no ha transcurrido como un fenómeno exclusivamente nacional, sino que se ha visto influido a veces $y$, determinado, en otras ocasiones, por los acontecimientos del exterior, como consecuencia de la creciente integración de la economía española en la Unión Europea, especialmente a raíz de la incorporación de la peseta al mecanismo de cambios del Sistema Monetario Europeo en 1989 y la posterior liberalización de los movimientos de capitales en 1992, acontecimientos que se vieron culminados con la entrada en vigor del Mercado único financiero en 1993 y, más tarde, en 1999, por la incorporación española a la Unión Económica y Monetaria (UEM). Todo esto ha provocado que los mercados monetarios españoles hayan ido siendo cada vez menos españoles y más europeos, hasta llegar a una situación en la que, por ejemplo, los tipos de interés negociados en ellos se encuentran en valores muy cercanos a los existentes en los países de nuestro entorno, lo cual no cabe duda de que ilustra el proceso de convergencia de la economía española.

En este contexto debe tenerse muy presente la importante transformación que ha supuesto para estos mercados la fecha del primero de enero de 1999, la cual ha marcado el inicio de la tercera fase de la UEM. Con su entrada en vigor, se han producido una serie de modificaciones en varios aspectos que 
determinan las características de estos mercados: la moneda en la que se denominan los instrumentos y se efectúan las transacciones, la existencia de una autoridad monetaria común para todo el área euro, el diseño de una nueva forma de realizar la política monetaria, etc.

Todo esto ha reforzado aún más si cabe el proceso que antes se indicaba por el que estos mercados eran cada vez más europeos y les hace situarse en una posición en la que to do el grado de desarrollo alcanzado durante los años anteriores no se puede considerar como un objetivo ya cumplido. Al contrario, este proceso de crecimiento y consolidación, debe ser el punto de partida ante un ámbito de actuación mucho más amplio, pues la economía española en su conjunto ( $y$, lógicamente, también los mercados financieros españoles) se encuentra inmersa en un entorno cada vez más abierto y competitivo. Por lo tanto, en el futuro se deben seguir produciendo nuevos avances para que los mercados monetarios españoles puedan cumplir las funciones a las que antes se hacía referencia y alcancen un grado de madurez adecuado.

Dada la amplitud de los aspectos a los que se puede hacer referencia al analizar la formación y evolución de los mercados monetarios a lo largo de los últimos años, en los epígrafes siguientes se recogen algunos de los que se pueden resaltar como más importantes e interesantes. Debido a la trascendencia que ha supuesto para estos mercados la incorporación a la Unión Monetaria (UM) se han separado los referidos a los mercados hasta el 31 de diciembre de 1998, de los correspondientes a la situación posterior a esta fecha. Además, se hacen referencias al conjunto de los mercados, así como comentarios diferenciados (cuando procede) relativos a los dos grupos considerados: el de los mercados de activos de caja y el del resto de los mercados que abarcan los instrumentos emitidos a corto plazo.

\section{Los mercados monetarios hasta 1998}

Como ya se ha indicado, si hay algo que probablemente define de forma breve la situación de los mercados monetarios antes de 1999 es el elevado grado de desarrollo que han alcanzado. En efecto, si se consideraúnicamente el saldo vivo de los mercados de activos de caja y de los restantes mercados monetarios entre 1984 y 1998, éste prácticamente se ha multiplicado por seis, mientras que si se observa la negociación en los mismos ${ }^{17}$ el crecimiento es

17 Los volúmenes negociados aparecen más adelante, en los cuadros 2 y 4. 
aún más espectacular cuando se tienen en cuenta las operaciones dobles en el mercado de deuda anotada que es el que ha experimentado un aumento más elevado de la contratación.

Por otra parte, debido a las variaciones que han experimentado las condiciones de la coyuntura económica en España en los últimos años (en los que el proceso de convergencia hacia la Unión Económica y Monetaria ha propiciado la reducción de las tasas de inflación, de déficit público y de los tipos de interés), se ha producido también un aumento de la preferencia por los valores a medio y largo plazo, en detrimento del corto plazo, lo que ha originado que las emisiones de los valores propios de estos mercados hayan experimentado en los últimos años una reducción con respecto a los valores máximos alcanzados en los primeros años de la década de los 90.

El desarrollo al que antes se hacía referencia no sólo es apreciable por el volumen alcanzado por estos mercados; además, ha venido acompañado de un aumento en el número de los instrumentos propios de los mismos, pues se ha pasado de la existencia de un mercado puramente interbancario en el que las entidades se intercambiaban sus excedentes de liquidez, a un conjunto de mercados en los que intervienen, además de las instituciones financieras, las administraciones públicas (Estado, Comunidades autónomas y Corporaciones locales) y las empresas no financieras como agentes con necesidades de recursos (es decir, como demandantes de financiación).

Por otro lado, a pesar de que los mercados monetarios españoles se han ampliado, en el sentido de superar el concepto de mercado puramente interbancario, si se observa el conjunto de los mismos, es claramente apreciable que hasta 1998, el papel central (y casi único) en este conjunto de mercados ha correspondido, tanto al mercado de depósitos interbancarios, como al mercado de deuda pública anotada (casi exclusivamente deuda del Estado).

Con respecto al mercado de depósitos, se puede decir que fue el primero de los mercados monetarios españoles y, a pesar de los intentos realizados para mejorar las características del instrumento negociado ${ }^{18}$, ha mantenido las características básicas que le caracterizaron desde el principio. Su

18 Fruto de este deseo fue la creación de los depósitos interbancarios transferibles en 1992, los cuales no han llegado a alcanzar la importancia que tienen instrumentos similares en otros países ni tampoco han logrado ocupar una parte relativamente importante en la negociación dentro del mercado lo que ha provocado la práctica desaparición de estos instrumentos. 
importancia se relaciona con varias circunstancias, entre las que pueden destacarse: su vinculación con la gestión de la tesorería de las entidades, el haberse convertido en un lugar que el que también se produce un intercambio de financiación de carácter más estable entre las entidades financieras y su estrecha relación con la política monetaria practicada por el Banco de España.

En cuanto al mercado de deuda pública, ha sido el otro gran protagonista del desarrollo de estos mercados, si bien en los últimos años las transacciones relacionadas con los instrumentos a corto plazo han perdido parte de su importancia relativa. Este papel central de este mercado se explica, por el elevado crecimiento del déficit y de la deuda pública desde la década de los 80 , los cuales mantuvieron unos valores muy elevados hasta principios de la primera mitad de los 90, unido a la decisión del Estado de cubrir sus necesidades de recursos en condiciones de mercado, abandonando paulatinamente la financiación privilegiada mediante la apelación al Banco de España o mediante coeficientes ${ }^{19}$.

Estos aspectos se han visto unidos a las preferencias del público por los valores emitidos por el sector público (adquiriéndolos de forma directa o bien indirectamente a través de las instituciones de inversión colectiva o de las entidades de depósito) debido a diferentes causas: sus condiciones atractivas en cuanto a la rentabilidad que ofrecían, su tratamiento fiscal diferenciado o incluso el mismo interés de las entidades en promocionar estas operaciones del público 20 .

Esta elevada presencia del sector público en los mercados monetarios no obedece exclusivamente, ni tampoco en su mayor proporción, a la importancia de los valores a corto plazo emitidos por el Estado, a pesar de que desde

19 Este cambio en la forma de financiación del Estado le vino impuesta por la pertenencia de España a la entonces Comunidad Económica Europea, la cual se encaminaba al establecimiento en 1993 del mercado único financiero, y por la ratificación del Tratado de la Unión Europea (el Tratado de Maastricht) que prohibe la financiación del Estado por el banco emisor.

20 A las entidades de depósito les ha interesado realizar cesiones temporales con su clientela debido a que éstas no estaban sometidas al coeficiente de caja. Por otra parte, en el crecimiento experimentado por los fondos de inversión en los últimos años, las entidades (sobre todo los bancos), han jugado un importante papel puesto que han apostado claramente por estas instituciones. Además, también el Estado contribuyó a este proceso puesto que su tratamiento fiscal era más favorable que el aplicado a otras formas de inversión financiera. 
1984 hasta 1992 la financiación que obtuvo provino fundamentalmente de los pagarés y letras del Tesoro. La causa fundamental que explica este predominio del mercado de deuda pública se encuentra en el extraordinario crecimiento experimentado por los mercados secundarios en los que las operaciones (en su mayor parte repos y simultáneas) se han realizado fundamentalmente a corto plazo (aunque el valor objeto de la operación tenga un vencimiento a largo plazo), por lo que se incluyen dentro del ámbito de los mercados monetarios.

El mencionado crecimiento de estas operaciones se relaciona con varios aspectos, que a su vez, explican también la facilidad con la que el sector público ha podido colocar los valores emitidos, tanto a corto como a medio y largo plazo: el empleo de estas operaciones por parte del Banco de España para facilitar liquidez a las entidades y por las propias entidades para efectuar su gestión de tesorería de forma alternativa a la realización o aceptación de depósitos interbancarios, ha hecho necesario que la cartera de deuda de las entidades deba ser elevada; por otro lado, las cesiones temporales de estos valores tanto a la clientela del sector familias como, en mayor medida, a los fondos de inversión, han contribuido también en el mismo sentido.

Además, desde el punto de vista de los aspectos organizativos e institucionales del mercado, debe indicarse en primer lugar que, con la creación en 1987 del Sistema de anotaciones en cuenta de deuda del Estado (que luego daría lugar al actual mercado oficial de deuda pública en anotaciones), se dio un gran paso para la modernización de este mercado, lo que no sucedió de igual forma en el caso de los mercados de renta fija privada. La desmaterialización del título-valor que supuso la creación de las anotaciones en cuenta como forma de representación de la deuda ha supuesto una mayor agilidad en el funcionamiento del mercado, al tiempo que ha reducido los costes del proceso de liquidación y compensación de las operaciones y ha aumentado la eficiencia de dicho proceso ${ }^{21}$.

Por lo que se refiere a la organización del mercado, el hecho de que sólo puedan ser miembros del mismo (principalmente) las instituciones financieras junto con el Banco de España, ha permitido la creación de un mercado muy institucionalizado y de tipo mayorista, lo que se ha traducido en un

${ }^{21}$ En el caso de los pagarés de empresa tan sólo recientemente se ha optado por la anotación en cuenta, estando materializados hasta ese momento como títulos físicos. 
crecimiento continuado de la negociación, que ha ido unido a una mayor transparencia de las operaciones, y a una mayor liquidez y profundidad. Por otro lado, la articulación de tres ámbitos de negociación, dos de ellos interconectados entre sí por ser en los que participan los miembros del mercado y un tercero en el que interviene el público, ha supuesto que las operaciones realizadas entre dichas entidades sean las que formen la estructura de precios y de tipos de interés de la deuda que luego servirán como referencia para la negociación con los agentes que no son miembros del mercado (los denominados terceros).

Esta mejora de los aspectos organizativos e institucionales ha servido, en parte, como acicate para la mejora de los mercados de renta fija en España, aunque el resultado en cuanto a su importancia relativa dentro de los mercados monetarios no haya sido muy elevada hasta 1998, y se ha plasmado en la creación del mercado de la Asociación de intermediarios de activos financieros (AIAF), el cual ha tenido hasta 1998 la categoría de mercado secundario organizado no oficial. El origen de este mercado se encuentra en el inadecuado funcionamiento del mercado bursátil de pagarés, lo que había impulsado la realización de las operaciones entre las instituciones financieras y al margen del ámbito más organizado constituido por la bolsa. Por esta razón el Banco de España apoyó la creación de la Asociación y, posteriormente, de este mercado que desde el principio tuvo un carácter mayorista. Esto ha dado lugar a una segmentación de los mercados secundarios de pagarés de empresa, lo que probablemente pueda haber frenado en parte el desarrollo de este instrumento.

Asimismo, la escasa importancia relativa de los mercados de los valores a corto plazo emitidos por agentes distintos del Estado (tanto los intermediarios financieros, como otras administraciones públicas y las empresas no financieras), puede tener su origen en otras circunstancias, tales como la complejidad de los trámites exigidos para llevar a cabo las emisiones, el escaso interés por parte de los emisores en acudir a esta fuente de recursos, y el reducido grado de desarrollo, liquidez y eficiencia que han caracterizado a los mercados de renta fija privada españoles.

\subsection{Los mercados de activos de caja hasta 1998}

A pesar de que en las líneas anteriores se han realizado algunas referencias a los mercados de activos de caja, se completan aquí con algunos aspectos destacables de su formación y desarrollo hasta 1998. 
- La ejecución de la política monetaria a lo largo de estos años ha sido la determinante de la evolución de los distintos mercados de activos de caja, pues ha condicionado los tipos de operaciones realizadas, la periodicidad de las mismas, los instrumentos empleados, las instituciones participantes en los mercados, etc. Además, se ha visto condicionada, cada vez en mayor medida, por la situación en los mercados cambiarios como consecuencia de la incorporación de la peseta al mecanismo de cambios del SME (ello ha obligado a que algunas decisiones adoptadas estuvieran sujetas a limitaciones derivadas de esta restricción).

- Se ha producido una creciente integración de estos mercados en general, y del interbancario en particular, con el resto de los mercados financieros nacionales, muestra de lo cual es el hecho de que los tipos de interés de las operaciones negociadas en ellos se han ido consolidando, de forma progresiva, como un referente de los mercados crediticios y de otros mercados (como los de los valores públicos a corto y largo plazo). A su vez, la situación en estos mercados ha condicionado en parte la evolución de los mercados de activos de caja en la medida en que han originado cambios en la actuación del Banco de España.

- Por lo que se refiere a los tipos de interés de las operaciones ${ }^{22}$, se ha apreciado: su estrecha relación con los practicados por la autoridad monetaria (sobre todo en el caso de los tipos a un día), una influencia creciente de los tipos de interés internacionales ${ }^{23}$, así como la disminución progresiva de su variabilidad. En este sentido, si se analizan las diferencias existentes entre los tipos de interés de los depósitos interbancarios $^{24}$ y los de las cesiones y adquisiciones temporales entre las entidades, se observa que existe un diferencial positivo entre ambos tipos de operaciones ${ }^{25}$. Este diferencial obedece a la distinta garantía

22 Únicamente como ejemplo, en el gráfico 1 se recoge la evolución de los tipos de interés de los depósitos interbancarios a un día y los de intervención del Banco de España.

23 Sobre todo a raíz de la incorporación de la peseta al SME y, posteriormente, cuando se acercaba la entrada en funcionamiento de la Unión Económica y Monetaria.

24 Recordemos que desde 1984 la variable operativa (o instrumental) que controlaba el Banco de España eran los tipos de interés a corto plazo (un día) en el mercado interbancario de depósitos.

25 Es decir, los tipos de los depósitos han sido significativamente superiores a los de los repos, independientemente del instrumento que se haya empleado como colateral en estos últimos 
que ofrecen ambos tipos de operaciones (el depósito sólo ofrece una garantía personal, mientras que el repo cuenta con la garantía del instrumento financiero que es objeto de cesión), aunque en algún caso también han influido otros factores (en concreto, el saldo de la cartera de valores susceptibles de ser objeto de la operación).

\section{GRÁFICO 1}

\section{Evolución de los tipos de interés de intervención del Banco de España(*) y de los depósitos interbancarios a 1 día hasta diciembre de 1998}

(*) Hasta abril de 1990 corresponde al tipo de interés de los préstamos de regulación monetaria; desde mayo de 1990, se ha tomado el tipo de las subastas de certificados del Banco de España celebradas cada decena.

(Medias mensuales de datos diarios. Tipos de interés en \%)

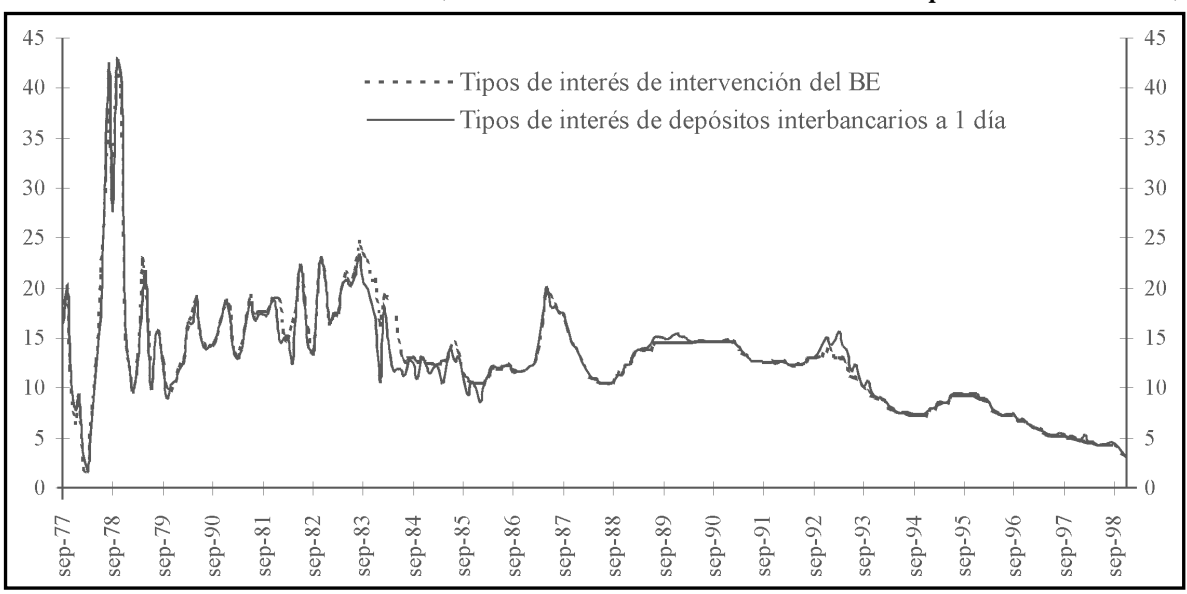

Fuente: Banco de España (varios años), Boletín estadístico y elaboración propia.

- En cuanto al volumen de las operaciones contratadas ${ }^{26}$, se ha observado un crecimiento acelerado de las mismas en el mercado interbancario a partir, sobre todo, de los años 1985-86. Las razones que han determi-

(que han sido los certificados del Banco de España, las letras del Tesoro y los bonos y obligaciones del Estado).

26 La negociación media diaria en estos mercados se recoge en el cuadro 2. 
nado este crecimiento se relacionan con: a) la participación creciente delos intermediarios financieros en el mercado; b) la mejora técnica del mismo; c) la disminución progresiva de los coeficientes de inversión obligatoria; d) los altos niveles de los tipos de interés presentes a lo largo de un gran número de años; e) los incrementos sucesivos en el nivel del coeficiente de caja, hasta 1990; y f) la extensión del mismo a un número cada vez mayor de entidades financieras; todo ello unido a las fuertes necesidades de liquidez de las instituciones ${ }^{27}$. En el caso de las

\section{CUADRO 2}

\section{Evolución de la contratación media diaria de las operaciones en los principales mercados de activos de caja}

(Medias anuales de datos diarios. Importes en m.m. ptas.)

\begin{tabular}{|c|c|c|c|c|c|c|c|c|c|}
\hline \multirow{2}{*}{ Fecha } & \multirow{2}{*}{\begin{tabular}{|c|} 
Depósitos \\
interbancarios \\
no transferibles
\end{tabular}} & \multirow{2}{*}{\begin{tabular}{|c|}
$\begin{array}{c}\text { Depósitos } \\
\text { interbancarios } \\
\text { transferibles }\end{array}$ \\
\end{tabular}} & \multirow{2}{*}{$\begin{array}{c}\text { Cesiones } \\
\text { temporales } \\
\text { de CBE }\end{array}$} & \multirow{2}{*}{$\begin{array}{c}\text { Pagarés } \\
\text { del Tesoro } \\
\text { (Repos) }\end{array}$} & \multicolumn{2}{|c|}{ Letras del Tesoro } & \multicolumn{2}{|c|}{$\begin{array}{c}\text { Bonos y obligaciones } \\
\text { del Estado }\end{array}$} & \multirow{2}{*}{ Total } \\
\hline & & & & & Repos & Simultáneas & Repos & Simultáneas & \\
\hline 1984 & 159,3 & $\overline{-}$ & - & 176,3 & - & 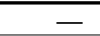 & - & - & 350,6 \\
\hline 1985 & 171,9 & - & - & 240,6 & - & - & - & - & 422,2 \\
\hline 1986 & 529,9 & - & - & 127,0 & - & - & - & - & 667,3 \\
\hline 1987 & 650,1 & - & - & 85,1 & - & - & - & - & 750,9 \\
\hline 1988 & 730,6 & - & - & 75,0 & 95,7 & - & 6,6 & - & 907,9 \\
\hline 1989 & 974,8 & - & - & 76,9 & 138,1 & - & 19,8 & 4,1 & $1.213,7$ \\
\hline 1990 & $1.063,7$ & - & 61,2 & 66,2 & 166,4 & - & 33,4 & 13,0 & $1.403,9$ \\
\hline 1991 & $1.307,7$ & - & 123,9 & 77,8 & 204,7 & - & 93,8 & 29,6 & $1.837,5$ \\
\hline 1992 & $1.304,9$ & 0,8 & 103,2 & 78,5 & 257,2 & - & 133,1 & 126,9 & $2.004,6$ \\
\hline 1993 & $1.698,6$ & 2,5 & 33,3 & 2,0 & 259,3 & - & 326,3 & 403,1 & $2.725,1$ \\
\hline 1994 & $1.670,5$ & 3,8 & 53,3 & - & 157,2 & - & 281,1 & 726,2 & $2.892,1$ \\
\hline 1995 & $1.550,8$ & 2,7 & 55,6 & - & 140,0 & 7,5 & 124,0 & 692,1 & $2.572,7$ \\
\hline 1996 & $1.837,2$ & 1,1 & 84,9 & - & 171,3 & 22,5 & 152,8 & 934,5 & $3.204,3$ \\
\hline 1997 & $1.951,6$ & 0,1 & 107,8 & - & 288,7 & 7,5 & 155,6 & $1.138,1$ & $3.649,4$ \\
\hline 1998 & $2.021,0$ & 0,0 & 18,9 & - & 191,2 & 14,9 & 95,9 & $1.287,5$ & $3.629,4$ \\
\hline 1999 & $1.416,8$ & 0,0 & 0,0 & - & 50,5 & 233,3 & 32,9 & $1.318,9$ & $3.052,4$ \\
\hline 2000 & $1.398,6$ & 0,0 & 0,0 & - & 28,6 & 246,0 & 74,5 & $1.862,9$ & $3.610,6$ \\
\hline
\end{tabular}

Notas: - La negociación de depósitos interbancarios transferibles comenzó en julio de 1992, por lo que para este año, la cifra se refiere únicamente al 20 semestre.

- Los repos y simultáneas con valores públicos se refieren a las operaciones realizadas entre entidades titulares de cuenta en la Central de anotaciones.

Fuente: Banco de España (varios años) Boletín estadístico, Banco de España (varios años)

Memoria de la Central de anotaciones y elaboración propia.

27 Sobre todo a partir de 1990, aunque estas necesidades de recursos no se han presentado de forma constante a lo largo de los años finales analizados. 
operaciones con valores emitidos por el Estado entre las instituciones financieras, se ha observado también un crecimiento importante a partir de los primeros años de la década de los 90 , sobre todo desde 1993, que es cuando se producen las mayores necesidades de recursos por parte de las entidades. Desdeesa fecha hasta 1998 se ha producido, además, un cambio en la instrumentación, pues inicialmente las operaciones más importantes eran los repos de letras del Tesoro y, posteriormente, pasan a serlo las simultáneas con bonos y obligaciones del Estado, como consecuencia del mayor volumen de deuda a medio y largo plazo en circulación y de los cambios experimentados por la instrumentación de las operaciones de política monetaria del Banco de España.

\subsection{Los mercados monetarios de valores a corto plazo hasta 1998}

En relación con este grupo de mercados, ya se ha comentado anteriormente la importancia relativa que tienen cada uno de ellos y como el protagonismo de los valores emitidos por el Estado determina que en los mercados primarios de valores a corto plazo las emisiones de los agentes distintos al Tesoro hayan sido muy reducidas, mientras que en los mercados secundarios el protagonismo de los valores públicos es aún mayor, debido al importante volumen de operaciones dobles (repos y simultáneas) que se han realizado por las entidades de depósito con su clientela del sector empresas no financieras y familias y con las instituciones de inversión colectiva en valores mobiliarios (sobre todo fondos de inversión).

Además de ello, resultan de interés algunos aspectos que se resumen en los párrafos siguientes:

- En relación con los instrumentos emitidos por el Tesoro, los pagarés del Tesoro fueron el primer valor emitido a corto plazo por el Estado con el objetivo deconstituir una fuente importante de recursos procedentes no sólo del sistema financiero, sino también del público en condiciones de mercado. Por otra parte, se convirtieron durante los años 1984-85 en la referencia de los mercados financieros españoles hasta que, a raíz de la entrada en vigor de la ley 14/85, su especial tratamiento fiscal hizo que dejaran de desempeñar el papel que habían tenido hasta ese momento (convirtiéndose en refugio del dinero negro) y que perdieran paulatinamente importancia conforme disminuía el coeficiente de inversión. 
Su lugar fue ocupado por las letras del Tesoro, creadas en 1987, las cuales se convirtieron en el período 1987-1991 en el instrumento de financiación más importante del Estado. Su emisión en condiciones de mercado (lo que se muestra, por ejemplo, en el hecho de que no fueran computables en ningún coeficiente de inversión obligatoria) y a corto plazo, supuso un hito importante porque constituían una forma de acercar el Tesoro a los mecanismos más ortodoxos de financiación y porque han permitido acercar los tipos de interés de los mercados financieros a los existentes en los mercados de activos de caja. Este proceso ha sido posible, por un lado, gracias a las características de las letras, en cuanto a importe y plazo, que han hecho de ellas un instrumento al alcance de todos los inversores; por otro lado, también ha influido su comercialización a través de las entidades de depósito, mediante la cesión temporal de su cartera.

- En cuanto a los instrumentos emitidos por los restantes agentes (otras administraciones públicas, empresas no financieras e instituciones financieras), normalmente se ha tratado de pagarés que presentaban unas características similares a las de los valores públicos, en cuanto a forma de emisión, importes, plazos, etc., si bien no han tenido el mismo tratamiento fiscal, lo que en principio les ha restado atractivo como forma de invertir los excedentes de los agentes y les ha obligado a aumentar la remuneración ofrecida, no sólo para compensar su mayor riesgo de crédito, sino también su diferente trato impositivo y las diferencias en el grado de liquidez y profundidad de su mercado secundario. Si se analiza esta circunstancia para las emisiones de los denominados principales emisores de pagarés durante el período 19871998, se obtiene como resultado que, en promedio, ha existido una prima de aproximadamente 0,5 puntos porcentuales para el plazo de emisión de un año, alcanzando valores superiores en los plazos de tres y seis meses. Además se puede apreciar que dicha prima iba descendiendo en los últimos años, tras alcanzar los máximos valores en el bienio 1989-90.

- En el grupo constituido por otros emisores de carácter público (comunidades autónomas y corporaciones locales) han sido muy pocos los que han empleado esta forma de financiación dadas las restricciones al endeudamiento que supone la legislación que les afecta. Por lo general, las emisiones se han realizado a unos tipos de interés muy próximos a los existentes en cada momento para las emisiones realizadas por el 


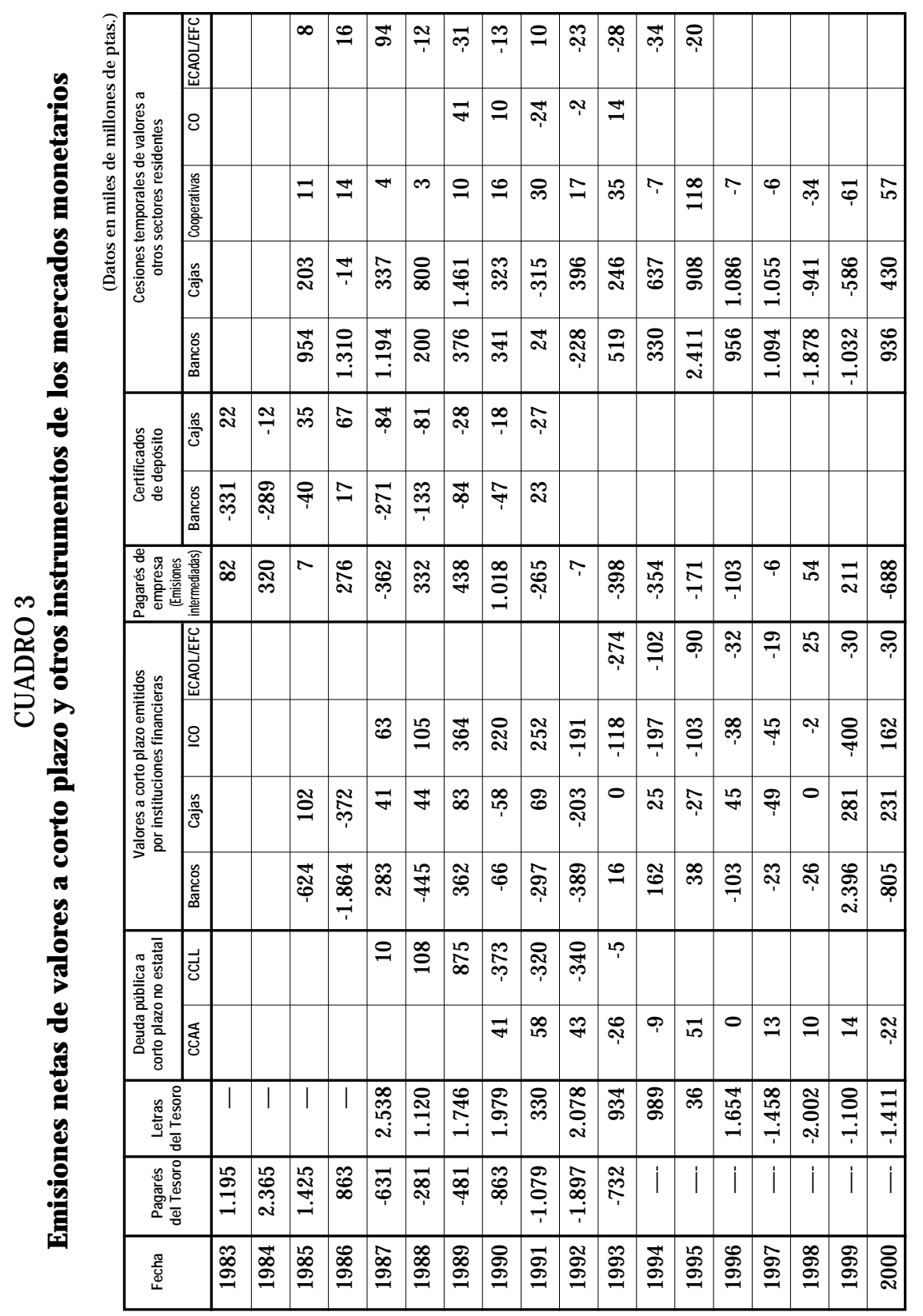

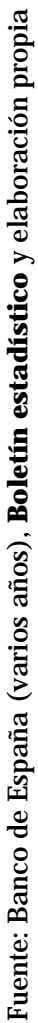


Estado a plazos equivalentes aunque, como es lógico (dados los diferentes grados de riesgo y de liquidez de estos valores en relación con los emitidos por el Estado), con valores ligeramente superiores a los de éstas ${ }^{28}$. Por último, en el caso de las instituciones financieras, el empleo de los valores a corto plazo como fuente de recursos no es muy habitual ni tampoco reviste una elevada importancia relativa; únicamente han sido empleados en mayor proporción por el ICO y por los establecimientos financieros de crédito (antiguas ECAOL), como consecuencia de las limitaciones que tienen para acceder a otras formas de financiación del público, como los depósitos.

- Por otro lado, también en relación con los tipos de interés del mercado primario de pagarés, se ha observado que, al menos para los grandes emisores, el empleo de estos valores ha podido constituir un ahorro de costes financieros, dado que, en promedio, han sido inferiores a los de las cuentas de crédito concedidas por bancos y cajas de ahorro en más de 2,5 puntos porcentuales.

- En cuanto a las cantidades puestas en circulación, han ido variando en función de la situación de los mercados financieros en lo relativo a la posibilidad de las empresas acceder a otros instrumentos financieros alternativos a los pagarés para la obtención de los recursos, a los valores de los tipos de interés a corto plazo y las expectativas de su evolución futura y a las condiciones de los valores que son sus sustitutos en las carteras de los inversores.

- Por lo que se refiere a los mercados secundarios, los más importantes son los de los valores emitidos por el Estado, en los que se pone de manifiesto un crecimiento de las operaciones con deuda a medio y largo plazo, como consecuencia del aumento del saldo vivo de estos valores. Además, se ha apreciado un progresivo acercamiento a las condiciones practicadas en las operaciones de las entidades con la clientela hacia los valores pactados cuando se trata de operaciones entre instituciones financieras, lo cual se encuentra relacionado con el crecimiento de las operaciones de los inversores institucionales, que se comprueba también al analizar el elevado importe medio de las operaciones realizadas.

28 Concretamente, en el caso de los pagarés emitidos por la J unta de Andalucía durante 1998, los tipos medios y marginales de las subastas han sido superiores a los de las letras del Tesoro, como promedio, entre 13 y 21 puntos básicos, según los plazos, produciéndose casi siempre como mínimo un diferencial positivo de alrededor de 9 puntos básicos. 


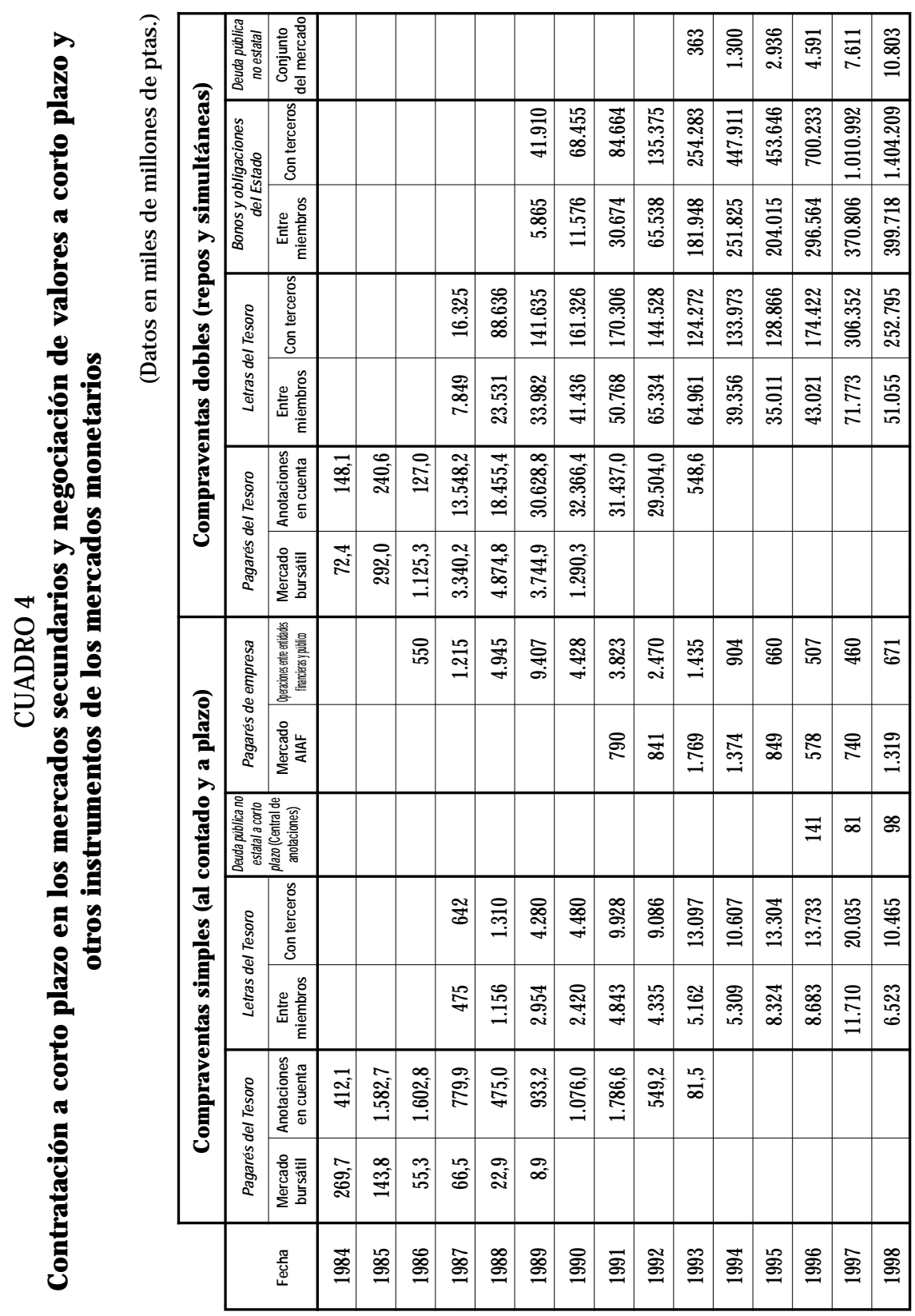

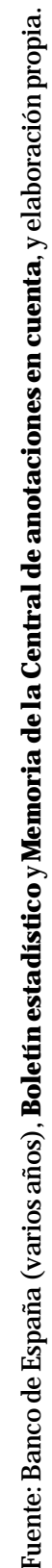


- En el caso del mercado secundario de pagarés emitidos por las comunidades autónomas, la negociación se ha llevado a cabo en la Central de anotaciones en cuenta y ha presentado como características más relevantes la ausencia de repos y simultáneas, lo que parece indicar que se trata de una forma de redistribución de los saldos adquiridos en el mercado primario por las entidades gestoras en el mercado de deuda anotada.

- Por último, para los pagarés de empresa, las transacciones del mercado secundario se han realizado en tres lugares distintos: la bolsa de valores ${ }^{29}$, el mercado de la AIAF y las operaciones entre las entidades y su clientela. En los dos últimos mercados citados la negociación ha tendido a disminuir desde los primeros años en los que se dispone de información hasta 1998, lo que pone de manifiesto que las operaciones realizadas dependen en gran medida del volumen de pagarés en circulación, el cual, a su vez, viene determinado por los importes emitidos.

\section{Los mercados monetarios en la Unión Monetaria}

El día 1 de enero de 1999 la situación de una parte de los países que formaban la Unión Europea cambió radicalmente puesto que ésta fue la fecha en la que comenzó la tercera fase de la Unión Económica y Monetaria. Uno de los acontecimientos más importantes en relación con este hecho fue que el SEBC comenzó su andadura efectiva como agente encargado del diseño y la realización de la política monetaria única, cuyas características, tanto las de tipo estratégico como las referidas a los instrumentos con los que se ejecuta, fueron fruto en gran medida del consenso entre los bancos centrales y las autoridades de los diferentes países.

A pesar de que la política monetaria de la zona euro es idéntica para todos los países, y la autoridad monetaria también lo es, el acuerdo adoptado respecto a la descentralización de las operaciones supone que no se han producido excesivos cambios en la vertiente institucional de la misma, pues

${ }^{29}$ Cuando comenzaron las operaciones con pagarés (en los primeros años de la década de los 80) éstas se realizaban en el mercado bursátil; sin embargo, aunque éste en sus inicios tuvo un éxito relativo, poco a poco fue perdiendo importancia (sobre todo por la complejidad de la operativa en cuanto a la admisión de los valores por la bolsa y la insatisfacción de los agentes con el funcionamiento del mercado bursátil de renta fija), hasta que finalmente desapareció. 
las entidades de crédito siguen relacionándose con su banco central. Sin embargo, aunque la política monetaria se realice de forma descentralizada en cada país por la autoridad monetaria que existía antes, en la actualidad, las decisiones relativas a la misma se toman de forma centralizada por el BCE, lo que supone que, en última instancia, éstas vienen impuestas desde fuera de los distintos países, lo cual es algo totalmente nuevo en todos los casos. En otras palabras, la auténtica novedad está en que la política monetaria es única para toda la Unión Monetaria.

Centrándonos en el caso español, los instrumentos de política monetaria que se aplican desde enero del año 99 presentan muchas líneas de continuidad con la gestión que hasta entonces había realizado el Banco de España, pues ésta se basa fundamentalmente en operaciones de mercado abierto resueltas mediante subastas públicas de carácter periódico ${ }^{30}$. A pesar de ello, sí que se han producido cambios y sehan debido producir adaptaciones, pues las entidades españolas han debido acostumbrarse, entre otros aspectos, al mantenimiento de un coeficiente de caja remunerado de cumplimiento mensual ${ }^{31}$ y a la periodicidad, el vencimiento y las garantías que se deben aportar para estas operaciones. Con todo, el elemento más novedoso para las entidades españolas es la existencia de las facilidades permanentes, que determinan un pasillo de tipos de interés dentro del cual se sitúa el tipo de interés de intervención del SEBC.

En cuanto a la evolución de los principales mercados monetarios durante los primeros meses transcurridos desde el comienzo del funcionamiento de la Unión Monetaria, ha habido algunas circunstancias que han afectado específicamente a los mercados españoles al ser una consecuencia de cambios o situaciones específicas de nuestro país; otras por el contrario han sido comunes a toda la Unión, precisamente por derivarse de la propia existencia de la misma. Ambos grupos, así como aquellos aspectos que pueden ser destacados como los más significativos de la evolución de los mercados a lo largo de este período, se resumen a continuación.

- El primer cambio que los mercados financieros españoles debieron acometer antes de enero de 1999 afectó principalmente a sus aspectos

30 Las características de las operaciones de la política monetaria única se describen en BCE (2000).

31 Antes de la UM, el coeficiente de caja era no remunerado y la mayor parte de las entidades debían cumplirlo con cómputo decenal. 
operativos y de funcionamiento con el objeto de adaptarse a la aparición del euro, que a partir de ese momento iba a constituir la nueva unidad de referencia prácticamente en todos ellos.

- Además de los cambios producidos como consecuencia de la entrada en la Unión Monetaria, han existido otros aspectos más específicos de la situación en España que también les han afectado. Algunos de ellos (principalmente cambios de la legislación que afecta a estos mercados) entraron en vigor en una fecha anterior al año 1999, sin embargo, los efectos que han ocasionado se han puesto de manifiesto a partir de este año. Por otra parte, ha habido otras circunstancias (no de carácter legislativo) que también han dejado sentir su influencia tanto en la parte final de 1998 como en los primeros momentos de 1999. De forma muy resumida, los principales aspectos específicos de la situación española, pueden sintetizarse en: a) la entrada en vigor de la reforma de la ley del mercado de valores y el desarrollo reglamentario de algunos de sus preceptos; b) la modificación del régimen fiscal de los instrumentos financieros; c) el fuerte ritmo de actividad económica en España que se ha traducido, entre otros aspectos, en una mayor necesidad de recursos por parte del sector privado (lo que ha impulsado la oferta de valores) y en unas menores necesidades de éstos por parte del sector público, con la consiguiente reducción de sus emisiones de valores.

- En cuanto a la evolución de los diferentes mercados monetarios, las rentabilidades negociadas en los mismos han venido determinadas fundamentalmente por los tipos de interés practicados por el BCE en la ejecución dela política monetaria32, los cuales mostraron valores descendentes en los primeros meses de 1999, para comenzar una senda ascendente en la parte final del mismo ejercicio como consecuencia del incremento de las tensiones inflacionistas en la zona euro; tan sólo a finales de 2000 se produjo una reducción de tipos (que se ha continuado durante el año 2001) al producirse cierta mejoría en la evolución de los precios. Esta misma tendencia es la que se ha apreciado en los diferentes mercados analizados aunque los incrementos señalados se produjeron en diferentes momentos del tiempo (normalmente estos aumentos se adelantaron en los instrumentos y operaciones cuyos plazos eran mayores) ${ }^{33}$.

32 Sobre la ejecución de la política monetaria por el BCE durante los primeros meses de la UM puede consultarse A. Rodero y M. C. López (2000).

33 La evolución de algunos tipos de interés a corto plazo se han recogido en el gráfico 2. 


\section{GRÁFICO 2}

Tipos de interés marginales de las emisiones de letras a un año, de intervención del BCE y de los depósitos interbancarios a un día en el segmento español

(Medias mensuales de datos diarios. Tipos de interés en \%)

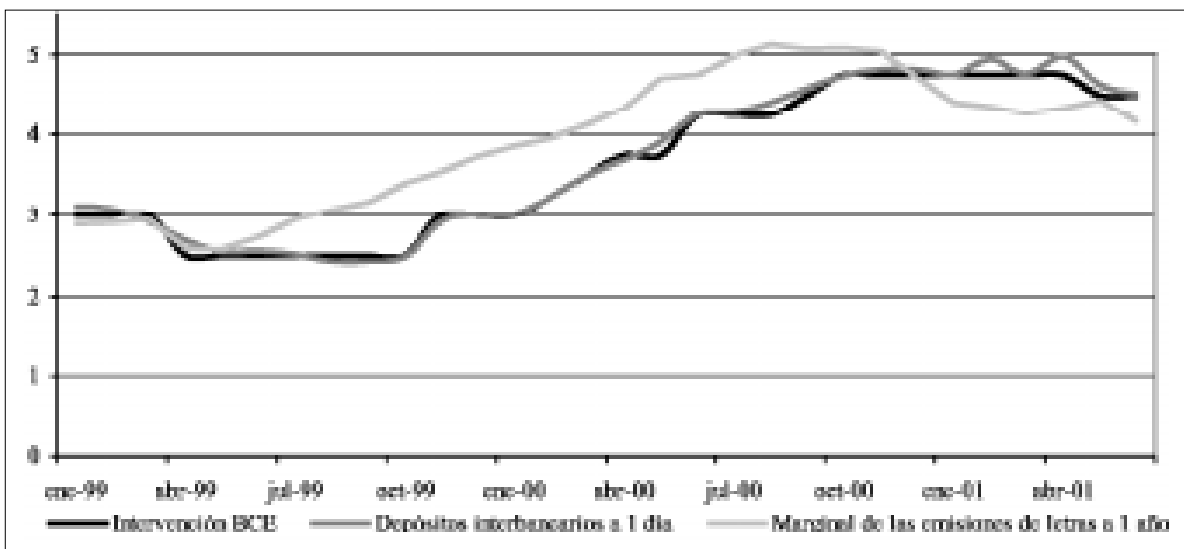

Fuente: Banco de España (2000), Boletín estadístico y BCE (2000), Boletín mensual.

Por lo que se refierea la evolución de los volúmenes contratados, cabría distinguir la diferente situación de los tres mercados principales analizados (entendidos en el sentido de centros de negociación). Así, en el caso del mercado interbancario de depósitos, el haberse constituido un mercado en euros más amplio que abarca el conjunto de la Unión Monetaria ha traído consigo un descenso en la negociación en lo que queda como segmento español. En el mercado de deuda pública, las menores necesidades de recursos de las administraciones públicas en general han ocasionado que en el mercado primario se produzca un descenso de las emisiones y, en el caso concreto de los valores a corto plazo, una disminución del saldo vivo de los mismos. Esta menor actividad del mercado primario también se ha dejado notar en el mercado secundario, en el que, considerando to das las operaciones, se observa una tendencia al descenso de la contratación, aunque en algunas modalidades concretas se haya producido un aumento ${ }^{34}$. Por

${ }^{34}$ Además, en esta tendencia ha influido también en parte la nueva instrumentación de la 
último, en los otros mercados de renta fija a corto plazo (cuyas operaciones del mercado secundario se realizan principalmente en el mercado AIAF), debe destacarse, en primer lugar, el fuerte incremento de la actividad del mercado primario, que no solamente se ha producido en relación con los importes puestos en circulación, sino que también ha venido acompañado de un aumento de los agentes emisores $^{35}$. Igualmente, también se ha producido un crecimiento que en el mercado secundario, que ha visto como sus niveles de contratación experimentaban un fuerte impulso.

\section{Algunas consideraciones acerca del futuro de los mercados monetarios españoles}

En las líneas anteriores se han puesto de manifiesto algunas características de los mercados monetarios que suponen una continuidad con respecto a las que existían antes del funcionamiento de la UM; otras, por el contrario, han supuesto una variación de dicha situación y, en consecuencia, se han manifestado como una novedad que, probablemente siga existiendo de aquí en adelante. A partir de todas ellas es posible realizar algunos comentarios relacionados con lo que puede ser el futuro de los mercados monetarios españoles y los aspectos más importantes de su comportamiento.

Evidentemente, dicho comportamiento futuro está condicionado por la existencia de la Unión Monetaria, la cual va a determinar en gran medida el contexto en el que estos mercados se van a desenvolver. Por esta razón, es necesario hacer una primera referencia a la misma, pues afecta de forma directa a varios de los mercados que se han analizado. Así, en primer lugar, la persistencia de la autoridad monetaria única para toda la Unión y la generali-

política monetaria que, al exigir unas mayores cantidades de valores aportados como garantía, ha hecho que las operaciones con estos títulos sean más reducidas, al menos en el caso de aquellas en las que una de las partes (o las dos) son instituciones financieras monetarias (que son las que pueden tener acceso a la financiación por el Eurosistema).

35 Este aumento ha venido como consecuencia de varios factores entre los que destacan: a) las mayores necesidades de recursos de los agentes (empresas no financieras y entidades de crédito); b) los cambios experimentados en el funcionamiento de los mercados secundarios; c) la eliminación del riesgo cambiario de las emisiones al realizarse prácticamente todas ellas en euros; d) los niveles históricamente mínimos alcanzados por los tipos de interés; e) las menores emisiones del sector público; f) la equiparación del tratamiento fiscal con la renta fija estatal; y g) las modificaciones efectuadas en la regulación del mismo mercado primario. 
zación de las transacciones en euros, sobretodo a partir del año 2002 en el que desaparecerán definitivamente las divisas nacionales y circularán únicamente billetes y monedas en euros, determinará que aumente la importancia del mercado interbancario global para toda la zona euro, mientras que probablemente disminuirá la importancia relativa de los diferentes segmentos nacionales, que quedarán más limitados a las operaciones de las entidades de menor tamaño y que no tengan tanta facilidad (bien por tener más dificultades en cuanto la aportación de garantías o bien por otros motivos) para operar en el ámbito más amplio ${ }^{36}$. A esta situación debe contribuir, además, la mejora del funcionamiento del sistema TARGET (que es el sistema de pagos de la Unión Monetaria), así como la generalización del empleo del mismo para realizar las transferencias entre las entidades de diferentes países.

En relación con esta misma circunstancia (disminución de la importancia relativa del segmento nacional del mercado interbancario) existen otros aspectos que también pueden influir en el mismo sentido, como son el mantenimiento dela inyección derecursos en conjunto para toda la Unión (esto es, sin llevar a cabo ningún reparto de los mismos entre las diferentes naciones que conforman la UM); el escaso uso que se ha hecho hasta el momento de las facilidades permanentes (lo que implica que las posibles necesidades a más corto plazo no se obtengan del banco central correspondiente sino que se cubran acudiendo a otras entidades); la desaparición de los posibles problemas de ajuste que probablemente se han producido en los momentos iniciales en algunas entidades de menor tamaño o con menor actividad transfronteriza (derivados de una posible falta de información y preparación suficiente); los posibles problemas derivados de la falta de colaterales, etc.

Otro aspecto relacionado con la Unión Monetaria que también va a determinar la situación en los mercados monetarios españoles se refiere al uso de los activos de garantía para acceder a la financiación del Eurosistema. En efecto, al ampliarse la gama de activos susceptibles de ser empleados como colateral en estas operaciones, se producirán varias consecuencias, algunas de las cuales ya han comenzado a manifestarse en los primeros meses anteriormente analizados: en primer lugar, esto supone un impulso a

36 También es posible que estas entidades de menor tamaño que, en principio, podrían estar sujetas a líneas de crédito más restrictivas, prefieran establecer algún tipo de convenio con una entidad mayor para efectuar la gestión de su tesorería, en lugar de participar por cuenta propia en el mercado. Esto, probablemente, acentúe aún más la pérdida de importancia de las operaciones realizadas en el segmento español. 
las emisiones de renta fija por parte de entidades privadas, dado que, en principio, pueden ser empleadas como colateral y por lo tanto aumenta su atractivo para las instituciones de crédito como potenciales inversoras por lo que se amplía la demanda de las mismas; en segundo lugar, se reducen las operaciones de cesiones temporales y simultáneas realizadas en el mercado secundario con los terceros que no son miembros del mercado, especialmente en el de los valores emitidos por el sector público, pues las entidades que hasta ahora las han realizado de forma mayoritaria (las entidades de depósito) tendrán un incentivo menor para llevarlas a cabo dada la necesidad de mantener un mayor volumen de los valores en cartera con el objeto de poder utilizarlos como garantía en las operaciones de política monetaria; en tercer lugar, y relacionado con lo anterior, las entidades de depósito deberán buscar otra fuente de recursos alternativa a las cesiones temporales y a las simultáneas realizadas con sus clientes, lo que puede dar lugar, no sólo a una vuelta a las operaciones de captación de fondos más tradicionales, como los depósitos, sino también a un aumento de las emisiones realizadas por las propias entidades o relacionadas con ellas.

Por último, y también relacionado con el proceso de Unión Monetaria, si bien no tanto en sus aspectos operativos sino en cuanto a las condiciones en las que se puede desenvolver la actividad económica, la existencia de una moneda única implica la desaparición del riesgo cambiario entre las divisas anteriormente en circulación en los países integrantes de la zona euro, lo que también traerá consigo (ya de hecho está sucediendo), que los tipos de interés de los diferentes instrumentos en cada uno de los países no vengan tan determinados por las circunstancias específicas del mismo. En particular, en el caso de la deuda emitida por los distintos estados, será su diferente calidad crediticia y las garantías con las que, en su caso, se emitan los valores, las principal es circunstancias que determinarán las diferencias entre los tipos de interés en cada país pero el punto de partida, entendiendo como tal la situación en lo que se refiere a los tipos de interés a más corto plazo, es algo común para toda la zona euro, pues viene determinado por la actuación del BCE.

Esta circunstancia, en el caso español ha determinado que la situación actual sea de unos tipos de interés que han alcanzado sus mínimos históricos, presentando también unas diferencias relativamente estables con relación a los valores alcanzados por las rentabilidades en los países centrales de la UM (como Francia y Alemania). Por otra parte, en el resto de los instrumentos ha existido un comportamiento paralelo al de la deuda pública 0 al de los tipos a corto plazo, aunque como es lógico han existido diferenciales positivos con 
respecto a aquéllos debido a las características específicas de cada uno de estos instrumentos (motivadas fundamentalmente por su mayor riesgo, su distinto grado de liquidez y profundidad del mercado en el que se emiten y negocian y su diferente estructura en cuanto a los flujos devengados).

Además, en relación con este último aspecto, hay que tener en cuenta que la pertenencia española a la Unión Monetaria lleva consigo unos compromisos para el sector público relacionados con el cumplimiento del Pacto de Estabilidad y Crecimiento que provocarán una tendencia a reducir las emisiones de deuda pública, con lo que el peso de la misma en los mercados financieros se irá reduciendo (tal y como ya ha sucedido en 1999), dejando más espacio para las emisiones privadas, las cuales, en un entorno de estabilidad económica, se verán favorecidas al ofrecer una mayor rentabilidad como consecuencia de su mayor riesgo. Lógicamente, esta circunstancia no es algo específico de la situación española, sino que es común a todos los países del área euro, aunque es cierto que el crecimiento de las emisiones españolas puede ser mayor en el futuro dado el escaso desarrollo que hasta ahora han tenido los mercados de deuda no estatal en España, lo que implica que su potencial de crecimiento es superior al de otros países.

Otra cuestión que debe tenerse en cuenta y que puede favorecer o frenar las tendencias apuntadas hasta ahora, es el grado de eficiencia en el funcionamiento de los diferentes mercados españoles, entendidos en el sentido de centros de contratación. Ya se ha indicado que, en este sentido, los mercados españoles no presentan desventajas respecto a sus homólogos europeos, por lo que el intenso proceso de competencia relacionado con la localización del negocio financiero en el ámbito internacional que se ha iniciado en 1999 no ha tenido aún efectos negativos sobre los mismos. Lo que sí sucede en España es que existe una cierta división entre la deuda pública y la privada, y de éstas con los valores de renta variable, la cual no resulta favorable por el incremento de los costes de las transacciones.

Por ello, los pasos que se iniciaron con el acuerdo entre AIAF, las bolsas de valores y el SCLV para crear una plataforma común de registro, compensación y liquidación que homogeneizara y simplificara estos procedimientos resultaron positivos y han contribuido a fortalecer aún más la posición de estos mercados. Posteriormente, se produjo una ampliación del acuerdo indicado para incorporar también a la Central de anotaciones en cuenta, lo cual no cabe duda de que es positivo desde el punto de vista de la integración de todos estos procesos para el conjunto de los mercados 
organizados españoles. Así, en junio de 2000 se acordó la creación de una sociedad promotora (cuya denominación es IBERCLEAR) encargada preparar todos los cambios necesarios para la constitución de una nueva sociedad que se encargue de unificar la gestión de todos los sistemas de liquidación españoles.

En este terreno, una de las primeras medidas adoptadas por IBERCLEAR ha sido unificar los sistemas de liquidación de valores de la renta fija empleando la plataforma técnica de la Central de anotaciones del Banco de España para registrar y liquidar los valores de renta fija negociados en el mercado de deuda pública, en las bolsas de valores y en el mercado AIAF. Se ha terminado así con una separación entre este sistema para la deuda pública y la privada que, hasta el momento, sólo persistía, dentro de la UE, en España y en Bélgica.

Además del proceso indicado, también durante el año 1999 se llevaron a cabo otros procesos que modificaron la negociación de la deuda pública, al fusionarse las cuatro redes de pantallas de los brokers ciegos en una sola plataforma electrónica de negociación, denominada SENAF (Sistema Electrónico de Negociación de Activos Financieros) a la que tienen acceso los negociantes de deuda ${ }^{37}$. Esta modificación, sin duda importante, no ha quedado únicamente circunscrita al mercado de deuda pública pues en octubre de 2000, AIAF adquirió una participación mayoritaria en SENAF, con el objeto de que en un futuro muy próximo se llegue a un sistema único de negociación que agrupe tanto a la deuda pública como a la renta fija privada españolas. Además, en este contexto, debe tenerse en cuenta el acuerdo de integración firmado en abril de 2001 por parte de AIAF, SENAF y los mercados de futuros y opciones (MEFF), por el que se decidió crear un holding que fuera propietario de los tres mercados indicados. De esta forma se ha buscado combinar en un único grupo toda la negociación relacionada con la renta fija (pública y privada) y de derivados. ${ }^{38}$

37 En el mercado de deuda pública, una parte de las operaciones se realizan entre las entidades que son miembros del mercado a través de unos mediadores (brokers) que no facilitan la identidad de la otra parte de la operación. Esta característica (el desconocimiento de la contrapartida) hace que este segmento del mercado se denomine mercado ciego y que los mediadores que facilitan la contratación sean conocidos como brokers ciegos.

38 Posteriormente, en junio de 2001 se produjo la firma de un protocolo entre MEFF-AIAFSENAF y las bolsas con el objetivo de integrar tanto a los mercados devalores españoles como a los centros de liquidación. Sin embargo, esta integración parece aún algo lejana debido a los problemas que plantea el futuro papel que jugarán las bolsas autonómicas. 
Por otro lado, si se sigue generalizando la adopción de acuerdos entre las centrales depositarias de valores de la UE, como los suscritos en 1999 por la Central de anotaciones con algunas centrales europeas ${ }^{39}$, se sentarán las bases para llegar en el futuro a que se produzca la interconexión de estos mercados de renta fija en el ámbito de la UM, de forma similar a los acuerdos que se han firmado para algunas bolsas europeas. En cualquier caso, pensamos que este futuro mercado europeo queda aún algo lejano en el tiempo, aunque sí es posible que, a más corto plazo, se incorporen a EuroMTS un mayor número de referencias de deuda pública de los países de la UM, así como algunos de los valores de renta fija que emitan otros agentes privados de estos países que cumplan determinados requisitos en cuanto a tamaño de sus emisiones.

En resumen, se puede decir que el futuro más próximo de los mercados monetarios españoles puede venir caracterizado por algunos de los siguientes aspectos:

- Un mercado interbancario en el que se produzcan los intercambios de liquidez en euros entre las entidades de crédito cuyo ámbito será europeo, creciendo en tamaño a costa del segmento español de este mercado (cuyo ámbito será nacional, en el que se realizarán transacciones de menor volumen y cuya importancia cuantitativa será cada vez más reducida).

- Varios mercados de renta fija ${ }^{40}$ en euros que tenderán a estar integrados, probablemente de manera similar a como sucede actualmente con los valores de renta variable, de forma que las emisiones de instrumentos de renta fija de mayor volumen (entre las que se encontrarán las emitidas por el Estado y otros grandes emisores, como las grandes empresas, las entidades financieras y otras entidades públicas no

39 Estos convenios se firmaron con SICOVAM (Francia), Clearstream (Alemania), Monte Titoli (Italia) y Necigef (Holanda). Mediante los mismos se permite el registro y liquidación, en los sistemas extranjeros, de los valores registrados en la Central de anotaciones y, a su vez, que los valores registrados en las centrales objeto de los acuerdos, se trasladen a la Central de anotaciones para su registro y liquidación. De esta forma, los valores originalmente depositados en estas centrales que se registran en la Central de anotaciones, pueden ser utilizados como colateral frente al SEBC en las operaciones de política monetaria.

40 Nos referimos en general a la renta fija, porque los aspectos que se indican afectarán de forma global a todos estos instrumentos, aunque realmente sólo correspondan a los mercados monetarios los emitidos a corto plazo y las operaciones de los mercados secundarios realizadas también a corto plazo. 
estatales, como las CCAA y algunas CCLL) se negocien en un único ámbito (similar a lo que sería el mercado continuo), mientras que otras emisiones de menor entidad quedarían en otros mercados más especializados (como el mercado AIAF, cuya actividad es probable que sea inferior a la actual, actuando de forma parecida a como sucede actualmente con las cuatro bolsas tradicionales). En cualquier caso, la compensación y liquidación de todos estos valores se realizaría de forma centralizada. Además, algunas de las emisiones de mayor volumen podrían también negociarse de forma común para toda la UM.

- En relación con la importancia cuantitativa de los diferentes instrumentos, parece existir una tendencia hacia el aumento de las emisiones privadas a costa de las realizadas por el sector público, especialmente las realizadas por el Estado, lo que traerá consigo también un aumento paralelo en la negociación de la deuda no estatal a costa de ésta.

- En cuanto a los precios o rentabilidades negociados, como ya se ha indicado, los valores de referencia serán los determinados para toda la UM y, en el caso que nos ocupa, en el resto de los mercados monetarios, se producirán probablemente valores muy similares en los diferentes países, existiendo únicamente diferencias entre los tipos de interés de los distintos instrumentos, que obedecerán a sus aspectos más específicos, como el plazo de emisión, el grado de riesgo, la estructura de los flujos a percibir, el tratamiento fiscal, la liquidez y profundidad del mercado en el que se efectúan las transacciones, el volumen de las emisiones, etc.

\section{A modo de reflexión final}

Como final de este artículo, queremos hacer una breve reflexión crítica sobre el tema analizado. La existencia y el desarrollo de los mercados monetarios han contribuido a que se produzca un proceso de desintermediación bancaria, mediante el cual los agentes que necesitan los fondos se ponen en contacto directamente con los oferentes de éstos, prescindiendo de los intermediarios (en el caso español son sobre todo las entidades de depósito). Sin embargo, este proceso no ha sido muy importante pues si bien los intermediarios han visto reducida su importancia como prestamistas, han pasado a desarrollar otras actividades, lo que ha hecho que su intervención haya variado en cuanto a la forma, pero no que haya desapa- 
recido ${ }^{41}$. Por expresarlo con una sola frase: las entidades de depósito siempre ganan.

Por otro lado, el elevado desarrollo de los mercados de deuda pública, que en parte ha contribuido a consolidar dicho proceso de desintermediación, no debe ser considerado como algo totalmente positivo puesto que puede ser el origen, junto con otros aspectos, del escaso desarrollo del resto de los instrumentos analizados. Se podría, por tanto, decir que ha habido un cierto efecto expulsión, pues las emisiones del sector privado han debido competir con las del Estado, a veces incluso en desigualdad de condiciones, lo que les ha perjudicado ${ }^{42}$.

Cabría, finalmente, señalar otras dos cuestiones relacionadas con el escaso desarrollo de los mercados de renta fija españoles, tanto a corto, como a medio y largo plazo, que se refieren a la reducida financiación obtenida a través de ellos por dos sectores: las pequeñas y medianas empresas y las empresas procedentes de otros ámbitos geográficos, especialmente Latinoamérica. Respecto a las primeras, hasta ahora no han empleado las emisiones de valores, debido a las dificultades que han encontrado para emplear esta fuente de recursos, además de las reticencias que ellas mismas tienen hacia su uso; por ello, habría que buscar mecanismos para paliar esta situación. En cuanto a las segundas, quizás fuese posible establecer un mercado de pagarés de empresa y otros valores (que podría ser similar a Latibex) al que pudieran acudir.

\section{Bibliografía}

AiAf, Mercado de Renta Fija (varios años), Informe anual, varios números, Madrid, Ed. AIAF.

Ayuso, J., Fuentes, I., Peñalosa, J. M. y Restoy, (1999), El mercado monetario

41 El ejemplo más claro de esta circunstancia quizás sea el del mercado primario de pagarés de empresa, en el que normalmente los bancos siguen interviniendo para organizar el proceso de emisión, canalizar las peticiones, e incluso en algún caso garantizan las emisiones, lo que, evidentemente supone que la desintermediación como tal no se produce.

42 Recordemos, por ejemplo, que los pagarés de empresa no han gozado del mismo tratamiento fiscal que los pagarés del Tesoro o las letras del Tesoro, a pesar de tratarse de instrumentos con unas características similares a aquellos, por lo que, además de la necesaria prima que han ofrecido por su mayor riesgo, han tenido que aumentar esta prima para compensar el diferente trato impositivo que soportaban los inversores que los adquirían. 
español en la Unión Monetaria, Colección Estudios económicos no 67, Madrid, Ed. Banco de España, 74 págs.

Banco Central Europeo (2000), La política monetaria única en la tercera etapa. Documentación general sobre instrumentos y procedimientos de política monetaria del SEBC, Francfort, Ed. BCE, 98 págs.

BCE (2000), Informe anual 1999, Francfort, Ed. BCE.

BCE (varios años), Boletín mensual, varios números, Francfort, Ed. BCE.

BANCO DE España (varios años), Informe anual, varios números, Madrid, Ed. Banco de España.

Banco de España (varios años), Boletín estadístico, varios números, Madrid, Ed. Banco de España.

Banco de España (varios años), Memoria de la Central de anotaciones en cuenta de deuda pública, varios números, Madrid, Ed. Banco de España.

Comisión Nacional del Mercado de Valores (varios años), Informe anual sobre los mercados de valores, varios números, Madrid, Ed. CNMV.

Comisión Nacional del Mercado de Valores (varios años), Memoria, varios números, Madrid, Ed. CNMV.

BAnCo de España (1997), La política monetaria y la inflación en España, Madrid, Ed. Banco de España y Alianza editorial, 863 págs.

López M ARTín, Ma C. (2001), La creación de los mercados monetarios españoles. Formación y futuro, tesis doctoral, Córdoba.

Rodero Franganillo, A. y López Martín, Ma C. (1999), «La política monetaria en la Unión Monetaria Europea. Un enfoque espacial», Revista de Fomento Social, no 212, vol. 53, pp. 483-503.

Rodero Franganillo, A. y López Martín, MạC. (2000), «La ejecución de la política monetaria por el Banco Central Europeo y sus efectos en diversos países», Revista de Fomento Social, no 219, vol. 55, pp. 365-390.

Valero López, F., Cantalapiedra López, C., Lozano Almela, E. y Cano Martínez, D. (2000), La política monetaria en el área euro, Madrid, Ed. Analistas Financieros Internacionales, 154 págs.

Vera Santana, F. L. (2000), Guía para el mercado de valores en España, Madrid, Ed. Civitas, 412 págs. 